\title{
A Novel Combination Therapy for Human Oxaliplatin-resistant Colorectal Cancer Using Oxaliplatin and Coxsackievirus A11
}

\author{
BEIBEI WANG ${ }^{1 *}$, HISANOBU OGATA ${ }^{1,2,3^{*}}$, YUTO TAKISHIMA ${ }^{1,4}$, SHOHEI MIYAMOTO ${ }^{1,4}$, \\ HIROYUKI INOUE ${ }^{1,5}$, MASAKI KURODA ${ }^{1}$, KAZUNARI YAMADA ${ }^{1}$, \\ YASUKI HIJIKATA ${ }^{4}$, MUTSUNORI MURAHASHI ${ }^{3}$, HIROYUKI SHIMIZU $^{6}$, \\ TOSHIHIKO OKAZAKI ${ }^{3}$, YOICHI NAKANISHI ${ }^{5}$ and KENZABURO TANI ${ }^{1,3,4}$ \\ ${ }^{1}$ Division of Molecular and Clinical Genetics, Medical Institute of Bioregulation, and \\ ${ }^{2}$ Department of Medicine and Clinical Science, Graduate School of Medical Sciences, and \\ ${ }^{5}$ Research Institute of Diseases of the Chest, Kyushu University, Fukuoka, Japan; \\ ${ }^{3}$ Department of Advanced Cell and Molecular Therapy, Kyushu University Hospital, Fukuoka, Japan; \\ ${ }^{4}$ Project Division of ALA Advanced Medical Research, \\ the Institute of Medical Science, the University of Tokyo, Tokyo, Japan; \\ ${ }^{6}$ Department of Virology II, National Institute of Infectious Diseases, Tokyo, Japan
}

\begin{abstract}
Background: Colorectal cancer (CRC) is a major cause of morbidity and mortality throughout the world. It is the third most common cancer worldwide and the fourth most common cause of cancer-related death. FOLFOX, a combination of leucovorin calcium, fluorouracil, and oxaliplatin, is the first-line chemotherapy for stage III and stage IV CRC. However, patients with FOLFOX-resistant CRC have a poor prognosis. In recent years, virochemotherapy has been proposed as a potential treatment for chemotherapyresistant cancer. Materials and Methods: Through our first screening assay, we found that coxsackievirus All (CVAl1) displayed potent oncolytic activities. We tested whether coxsackievirus All (CVA11) has oncolytic activity in human $C R C$ cells in vitro and in vivo. We also examined whether pretreatment of oxaliplatin-resistant CRC cells with oxaliplatin enhances the oncolytic activity of CVA11. Results: We found that CVA11 was potently oncolytic against the oxaliplatinsensitive Caco-2 cell line, but had little effect on the oxaliplatin-resistant line WiDr. However, pretreatment of WiDr cells with oxaliplatin enhanced the oncolytic activity of CVA11, and the combination therapy was more cytotoxic than either
\end{abstract}

\footnotetext{
*These Authors contributed equally to this study.

Correspondence to: Kenzaburo Tani, MD, Ph.D, Division of Molecular and Clinical Genetics, Medical Institute of Bioregulation, Kyushu University, 3-1-1, Maidashi, Higashi-ku, Fukuoka 8128582, Japan. E-mail: k-tani@ims.u-tokyo.ac.jp
}

Key Words: Colorectal cancer, coxsackievirus, oncolytic virus. oxaliplatin treatment or CVA11 infection alone. Furthermore, growth of subcutaneous WiDr tumors in a xenograft model was significantly lower in mice treated with oxaliplatin followed by intratumoral CVA11 injection compared with mice receiving either treatment alone. Conclusion: Oxaliplatin pretreatment sensitized oxaliplatin-resistant CRC cells to lysis by CVA11 infection in vitro and in vivo. Taken together, these findings identify a novel potential chemovirotherapeutic modality for the treatment of oxaliplatin-resistant human CRC.

Adenocarcinoma of the colon and rectum (colorectal cancer, CRC) is the third most common cancer and the fourth most common cause of cancer death worldwide. Approximately 3.5 million people are currently living with $\mathrm{CRC}$, and there are an estimated 1.3 million new diagnoses and 0.7 million deaths from CRC annually (1). In Japan, treatment for CRC depends on the disease stage at initial diagnosis. Approximately $95 \%$ of stage I and $65-80 \%$ of stage II CRC cases are curable with surgery, which is the accepted treatment modality for earlystage CRC, but rectal cancer may require additional radiation therapy to minimize the risk of recurrence. Advanced-stage CRC (stages III and IV) is often treated with surgery, chemotherapy, and radiation therapy. Oxaliplatin, fluorouracil, plus leucovorin (FOLFOX) therapy has been shown to provide significant, but modest, improvement of disease-free survival for patients with CRC. However, patients with FOLFOXresistant CRC have the worst prognosis (2).

Oncolytic virotherapy using enteroviruses is a promising new strategy to treat various types of human cancers. RNA viruses seem to be a relatively safer modality, as most singlestranded RNA viruses replicate in the host cytosol without a 
DNA phase. Therefore, they lack the genotoxicity caused by integration of the viral genome into the host DNA (3). In particular, enteroviruses, members of the Picornaviridae family, a diverse group of small RNA viruses, have emerged as promising candidates for oncolytic virotherapeutic modalities. Their use has several therapeutic advantages: these viruses immediately induce robust cytolytic changes, they do not possess oncogenes that may lead to tumorigenesis, and they can be easily genetically manipulated by reverse genetics systems for the rescue of positive strand RNA viruses from complementary DNA. Furthermore, most non-polio enteroviruses are common and highly prevalent and are mainly associated with asymptomatic infection or mild diseases (4). Although coxsackievirus A21 is reported to be a potent oncolytic enterovirus against several types of human cancer cell, such as breast cancer, multiple myeloma and malignant melanoma, coxsackievirus A21-infected mice died of lethal myositis with paralysis (5).

In order to develop a novel virotherapy with an improved safety profile, we focused on an enterovirus strain of coxsackievirus A11 (CVA11), which has low pathogenicity, but possesses broad oncolytic activity against solid cancer, as demonstrated by our screen of 38 enteroviruses (data not shown). In the present study, we found that oxaliplatin pretreatment rendered an oxaliplatin-resistant CRC cell line sensitive to CVA11 oncolytic activity in vitro and in vivo.

\section{Materials and Methods}

Mice. Four-week-old female BALB/c nude mice were purchased from Charles River (Yokohama, Japan). All animal experiments (approval number: A26-086) were carried out under the Guidelines for Animal Experiments of Kyushu University and Law 105 Notification 6 of the Japanese Government.

Cell culture. The CRC cell lines WiDr and Caco-2 were purchased from the American Type Culture Collection (Manassas, VA, USA), expanded for one passage, and then frozen at $-80^{\circ} \mathrm{C}$ until use. Thawed cells were resuspended in Dulbecco's modified Eagle's medium supplemented with $10 \%$ fetal bovine serum and $1 \%$ penicillin-streptomycin, and then plated on $10-\mathrm{mm}$ diameter dishes at a density of $2 \times 10^{4}$ cells $/ \mathrm{cm}^{2}$. Cells were incubated at $37^{\circ} \mathrm{C}$ in a humidified atmosphere containing $5 \% \mathrm{CO}_{2}$.

Oxaliplatin. Oxaliplatin (Wako, Japan) was purchased from Seiko Co., Ltd, and used at $50 \mu \mathrm{M}$ for in vitro experiments and at $100 \mu \mathrm{g} /$ mouse for in vivo experiments.

Enterovirus. CVA11 (the prototype Belgium-1 strain) was obtained from H. Shimizu (National Institute of Infectious Disease, Tokyo, Japan) and was propagated in HeLa cells. The 50\% tissue culture infectious dose $\left(\mathrm{TCID}_{50}\right)$ per milliliter on HeLa cell monolayers was determined as previously described (6).

Cell viability. Cells were infected with CVA11 at multiplicity of infection (MOI) $0.1,0.01$, or 0.001 for $1 \mathrm{~h}$, and cell viability was assessed by crystal violet staining as previously described (7).
In vivo therapeutic study. WiDr cells $\left(5 \times 10^{6}\right.$ cells $)$ were injected subcutaneously into the right flanks of nude mice. When tumors reached a diameter of $0.4 \mathrm{~cm}$, mice were assigned to one of four treatment groups $(n=5)$ : untreated, or therapy with oxaliplatin alone, CVA11 alone, or the combination of oxaliplatin plus CVA11. Mice received an intraperitoneal injection of oxaliplatin $(100 \mu \mathrm{g} /$ mouse $)$ on day 1 with/without intratumoral injections of CVA11 $\left(4 \times 10^{4}\right.$ $\operatorname{TCID}_{50}$ ) on days $2,4,6,8$, and 10 . The tumor volume was calculated as (length $\times$ width $\times$ width) $/ 2$ as described elsewhere (6). Data are expressed as the means \pm standard error (SEM). Animals were euthanized when the tumor diameter exceeded $1 \mathrm{~cm}$.

RNA extraction and real-time reverse transcription-polymerase chain reaction $(R T-P C R)$. Total RNA was extracted from tumors from WiDr cells after $30 \mathrm{~h}$ incubation using an RNeasy Mini Kit (Qiagen, Hidden, Germany). RT was carried out using SuperScript III First-Strand Synthesis System (Thermo Fisher Scientific Inc. Waltham, MA, USA) according to the manufacturer's instructions. Quantitative real-time RTPCR was monitored using the StepOnePlus Real-Time PCR System (Thermo Fisher Scientific Inc., Waltham, MA, USA) and the results were analyzed with the accompanying software, as described elsewhere (8). Reactions were carried out in Taq Man PCR Master Mix (Foster City, CA, USA) with primers specific for human CD55 molecule (Cromer blood group) (CD55), intercellular adhesion molecule-1 (ICAM1), coxsackie and adenovirus receptor (CXADR), and P-selectin glycoprotein ligand-1 (SELPLG). Data are shown as the means \pm SEM.

Statistical analysis. All analyses were conducted with GraphPad Prism 5.0d software (GraphPad Software Inc., San Diego, CA, USA). Data were analyzed using two-tailed unpaired Student's $t$-test, one-way ANOVA followed by Tukey's multiple comparison test, or nonparametric Mann-Whitney $U$-test. A value of $p<0.05$ was considered statistically significant. Survival curves were plotted according to the Kaplan-Meier method (log-rank test).

\section{Results}

Oxaliplatin increases the oncolytic activity of CVAll against oxaliplatin-resistant CRC cells in vitro. We previously carried out a large-scale screening of enteroviruses to identify viruses with potent oncolytic activity against human cancer cell lines. Several enteroviruses displayed marked cytotoxic activity, particularly coxsackievirus B3, which was highly cytolytic against non-small cell lung cancer cell lines (6). However, we later found that wild-type coxsackievirus B3 caused unacceptable side-effects such as pancreatitis. Thus, we turned our focus to another enterovirus, CVA11, which was not expected to elicit similar side-effects. Using crystal violet staining to measure cell viability, we first examined whether CVA11 infection was oncolytic towards two human CRC cell lines, Caco2 and WiDr. We found that CVA11 was cytotoxic against $\mathrm{Caco} 2$ at a MOI as low as 0.001 (Figure 1A). Since Caco-2 is well-established as being sensitive to oxaliplatin, a standard chemotherapeutic agent for CRC (1), we also asked whether CVA11 was cytolytic against the oxaliplatin-resistant WiDr cell line, either alone or after pretreatment with oxaliplatin. Notably, CVA11 infection alone had little effect on the viability 


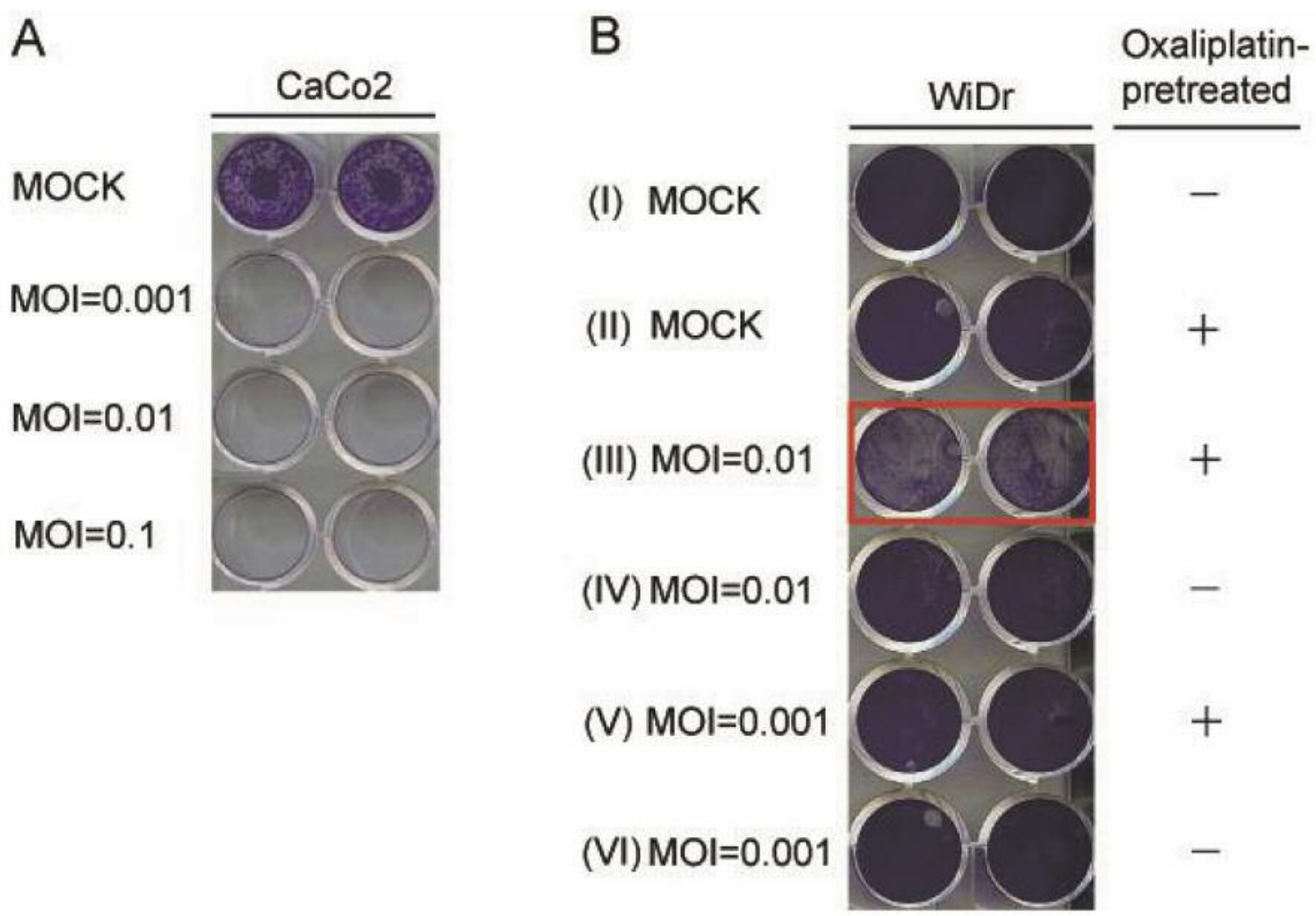

Figure 1. Oxaliplatin pretreatment increases the oncolytic activity of coxsackievirus A11 (CVA11). A: Caco2 cells were infected with CVA11 at a multiplicity of infection (MOI) of 0.1, 0.01, or 0.001, and cell viability was assessed $30 \mathrm{~h}$ later by crystal violet staining. B: WiDr cells were treated with oxaliplatin $(50 \mu M)$ for $12 \mathrm{~h}$ with/without infection with CVA11 for $30 \mathrm{~h}$ before measurement of cell viability. I: MOCK, no pretreatment or infection; II: pretreated with oxaliplatin only; III: pretreated with oxaliplatin and CVA11-infected at MOI 0.01; IV: CVA11-infected only at MOI 0.01; V: pretreated with oxaliplatin and CVA11-infected at MOI 0.001; VI: CVA11-infected only at MOI 0.001.

of these cells (Figure 1B). However, pretreatment with oxaliplatin for $12 \mathrm{~h}$ rendered WiDr cells sensitive to subsequent infection with CVA11, whereas oxaliplatin treatment or CVA11 infection alone had little effect on cell viability (Figure 1B).

Oxaliplatin improves the oncolytic efficiency of CVAl1 in oxaliplatin-resistant CRC xenografts in mice. We next investigated whether combination oxaliplatin and CVA11 therapy also had an enhanced activity against oxaliplatinresistant CRC xenografts in vivo. WiDr cells were injected subcutaneously into nude mice and the mice were then treated or not with oxaliplatin alone, CVA11 alone, or the combination of oxaliplatin plus CVA11. The results showed that tumor volumes were significantly smaller in mice treated with the combination therapy compared with either monotherapy $(p<0.05$, Figure $2 \mathrm{~A})$. None of the treatments affected the animals' body weights (Figure 2B). Mouse survival was assessed by the Kaplan-Meier method. This analysis revealed that mice in the combination group survived longer than mice in groups untreated, or treated with oxaliplatin or CVA11 alone (Figure 3).
Oxaliplatin induces expression of CD55 and ICAM1 in oxaliplatin-resistant CRC cells. In order to investigate the mechanism by which oxaliplatin pretreatment might enhance the oncolytic activity of CVA11, we examined the mRNA expression levels of the enterovirus receptors CD55, ICAM1, $C X A D R$ and SELPLG in oxaliplatin-resistant WiDr cells. SELPLG is an enterovirus 71 receptor required for viral replication in leukocytes (9), while CD55, ICAM1 and CXADR facilitate the entry of coxsackie viruses into the cells (10). After $30 \mathrm{~h}$ incubation, the relative expression levels of CD55 and ICAMI mRNA were significantly higher in oxaliplatin-treated cells compared with untreated cells (Figure 4).

\section{Discussion}

Standard chemotherapy against advanced CRC has only limited efficacy. Although FOLFOX is a standard treatment for stage III and IV CRC, patients with oxaliplatin-based chemotherapy-resistant advanced CRC have very poor prognosis (11). The antitumor effects of oxaliplatin are thought to be mediated by its biotransformation products, 

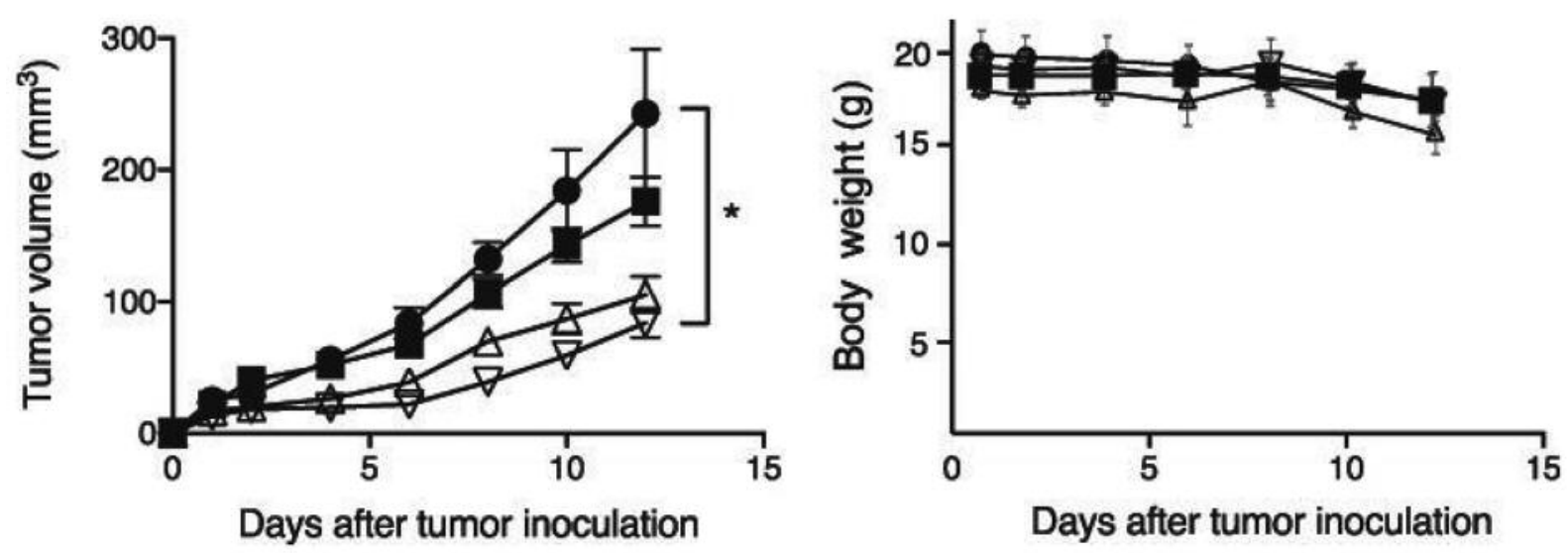

Figure 2. Oxaliplatin improves the oncolytic efficiency of coxsackievirus A11 (CVA11) in vivo. A: WiDr xenograft-bearing mice were assigned to four groups (n=5/group): untreated $(\mathbf{O})$, treated with oxaliplatin alone $(\mathbf{\square})$, treated with CVA11 alone $(\triangle)$, or treated with oxaliplatin followed by CVA11 infection $(\nabla)$. Mice were injected intraperitoneally with oxaliplatin (100 $\mu \mathrm{g} /$ mouse) on day 1 with/without intratumoral injection with $C V A 11$ (4x $\left.10^{4}\right)$ on days 2, 4, 6, 8, and $10(n=5)$. B: Body weights were measured on the indicated days. *Significantly different $p<0.05$. Data are shown as the means \pm SEM.

which induce cellular DNA damage. However, this also affects non-tumor cells and is the source of oxaliplatin toxicity (12). The cytotoxicity of oxaliplatin is approximately proportional to its cellular uptake (13).

Oncolytic viruses are viral strains that can infect and kill malignant cells without injuring normal cells. Oncolysis can be either a natural property of the virus or a consequence of manipulation of the viral genome, and oncolytic virotherapy has developed into an important modality for cancer treatment. Oncolytic virotherapy began in the early 1990s when a genetically modified, live-attenuated, thymidine kinasenegative herpes simplex virus (HSV) strain showed promising results in human glioma xenograft models (14). In 2015, TVEC (IMLYGIC ${ }^{\mathrm{TM}}$ ), a genetically engineered HSV, became the first oncolytic virus approved for use in the United States and the European Union for patients with locally advanced or non-resectable melanoma (15). Oncolytic viruses enter cells by binding to cell surface receptors or by fusion with the plasma membrane. An essential characteristic of an oncolytic virus is the ability to establish a lytic cycle in malignant tissues through an inherent tumor abnormality.

Oncolytic viruses have the ability to establish a niche of continuous viral replication within the tumor (16). Some oncolytic viruses, such as reovirus $(17)$, HSV $(18,19)$ and vaccinia virus (20), indirectly cause the death of malignant cells by inducing tumor-specific adaptive immune responses. Others, such as adenovirus (21), coxsackie virus B3 (6) and measles virus (22), cause endoplasmic reticulum stress and immunological cell death resulting from the release of molecules known as danger-association molecular patterns, including adenosine triphosphate, calreticulin, and highmobility group box-1, which attract immune cells (23). Combination treatment with an oncolytic virus and

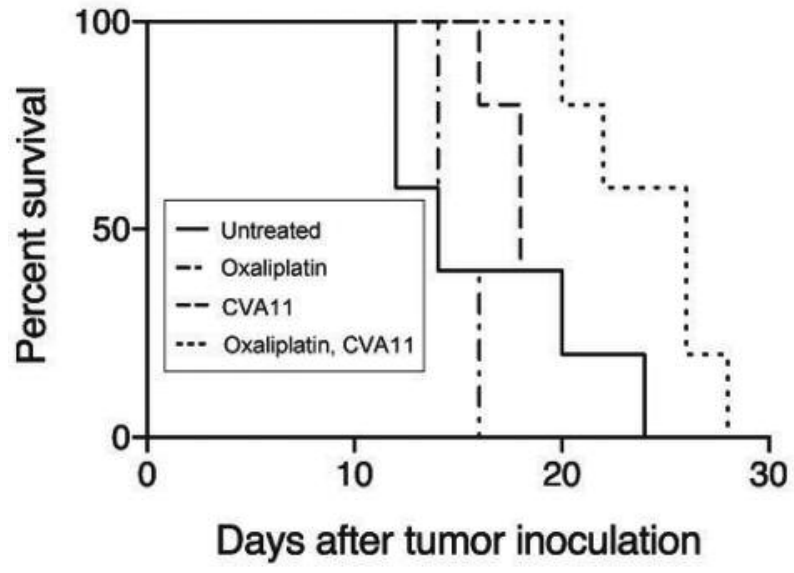

Figure 3. Oxaliplatin extends the survival of coxsackievirus A11 (CVA11)-treated mice. Kaplan-Meier survival analyses are shown for the groups of mice $(n=5)$ which were untreated, treated with oxaliplatin alone, treated with CVA11 alone, or treated with combined oxaliplatin pretreatment and CVA11.

chemotherapy was reported by Sung et al. in 2008 (24, 25), who showed that combination treatment with vesicular stomatitis virus (VSV) and cisplatin increased cancer cell death compared with VSV monotherapy both in vitro and in vivo. Although the mechanism of oncolysis of VSV was not clear, the combination therapy was thought to be immunomodulatory $(24,26)$. In our experiments, we found that oxaliplatin increased the oncolytic activity of CVA11 in oxaliplatin-resistant CRC cells in vitro and in the tumor xenograft mouse model. Importantly, serious side-effects were not observed in mice treated with the combination therapy. Our assessment of viral receptor expression 

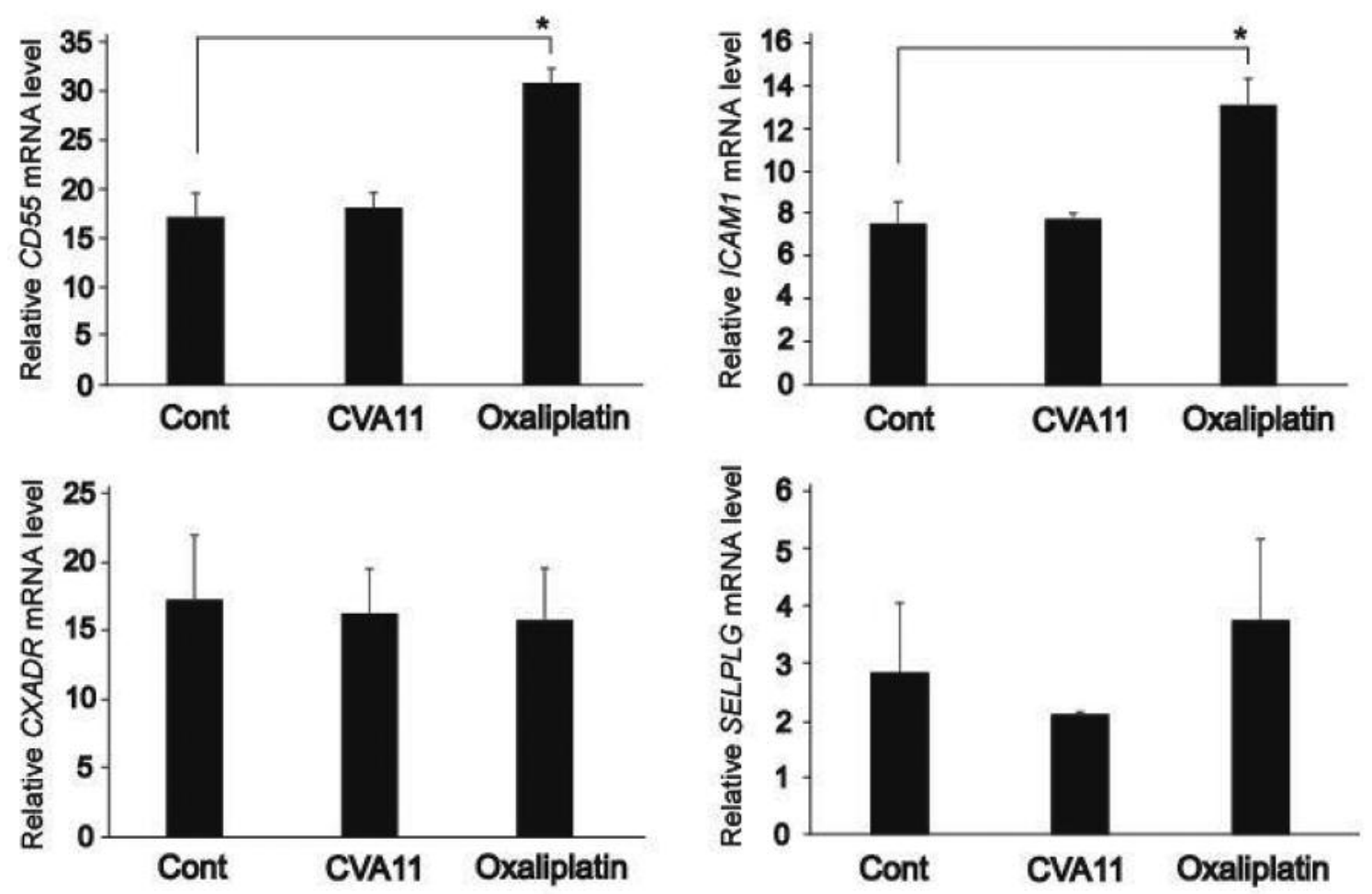

Figure 4. Oxaliplatin treatment enhances the expression of CD55 molecule (Cromer blood group) (CD55) and intercellular adhesion molecule-1 (ICAM1) viral receptors. Real-time polymerase chain reaction analysis was carried out of the relative mRNA expression of CD55, ICAM1, coxsackie and adenovirus receptor (CXADR), and P-selectin glycoprotein ligand-1 (SELPLG) in WiDr cells treated with oxaliplatin (50 $\mu M)$ or infected with coxsackievirus A11 (CVA11). Data are shown as the means \pm SEM, $n=4$. *Significantly different at $p<0.05$.

indicated that $C D 55$ and ICAMI were up-regulated by oxaliplatin treatment. Several cytokines have been reported to enhance the expression of both CD55 and ICAM1, including tumor necrosis factor- $\alpha(27,28)$, transforming growth factor- $\beta 1(29,30)$, and interferon- $\gamma(31,32)$. It is possible that oxaliplatin may have increased the expression of CD55 and ICAMI via up-regulation of cytokines, leading to enhanced oncolytic activity. However, the precise mechanism underlying the superior antitumor effects of the combination therapy remains unclear. A previous report suggested that SELPLG expressed on leukocytes might contribute to the replication of enterovirus 71 and the subsequent induction of cytopathic effect on infected cells (9). Based on our experiments, CD55 and ICAMI might contribute to the observed increase in CVA11-mediated oncolysis following oxaliplatin treatment.

In conclusion, in this study, we showed that CVA11 infection following oxaliplatin pretreatment was an effective therapy for human oxaliplatin-resistant CRC in mouse xenografts, raising the possibility that it may have a therapeutic potential. Further preclinical studies are required to validate this concept before starting clinical studies.

\section{Conflicts of Interest}

The Authors declare no conflicts of interest in regard to this study.

\section{Acknowledgements}

The Authors thank Ms. Haruka Yamato, Michiko Ushijima, and Michiyo Okada for their support. We also thank Anne M. O'Rourke, Ph.D., from Edanz Group (www.edanzediting.com/ac) for editing a draft of this article.

\section{References}

1 Gelband H, Jha P, Sankaranarayanan R, Gauvreau CL and Horton S: Summary. In: Cancer: Disease Control Priorities, Third Edition (Volume 3) (Gelband H, Jha P, Sankaranarayanan R, Horton S eds.). Washington (DC), 2015.

2 Song N, Pogue-Geile KL, Gavin PG, Yothers G, Kim SR, Johnson NL, Lipchik C, Allegra CJ, Petrelli NJ, O'Connell MJ, Wolmark N, and Paik S: Clinical Outcome From Oxaliplatin Treatment in Stage II/III Colon Cancer According to Intrinsic Subtypes: Secondary Analysis of NSABP C-07/NRG Oncology Randomized Clinical Trial. JAMA Oncol 2(9): 1162-1169, 2016. 
3 Pogue GP, Huntley CC and Hall TC: Common replication strategies emerging from the study of diverse groups of positivestrand RNA viruses. Arch Virol Suppl 9: 181-194, 1994.

4 Mao Q, Wang Y, Bian L, Xu M and Liang Z: EV-A71 vaccine licensure: a first step for multivalent enterovirus vaccine to control HFMD and other severe diseases. Emerg Microbes Infect 5: e75, 2016.

5 Kelly EJ, Hadac EM, Greiner S and Russell SJ: Engineering microRNA responsiveness to decrease virus pathogenicity. Nat Med 14: 1278-1283, 2008.

6 Miyamoto S, Inoue H, Nakamura T, Yamada M, Sakamoto C, Urata Y, Okazaki T, Marumoto T, Takahashi A, Takayama K, Nakanishi Y, Shimizu H and Tani K: Coxsackievirus B3 is an oncolytic virus with immunostimulatory properties that is active against lung adenocarcinoma. Cancer Res 72: 2609-2621, 2012.

7 Meng X, Nakamura T, Okazaki T, Inoue H, Takahashi A, Miyamoto S, Sakaguchi G, Eto M, Naito S, Takeda M, Yanagi Y and Tani K: Enhanced antitumor effects of an engineered measles virus Edmonston strain expressing the wild-type $\mathrm{N}, \mathrm{P}, \mathrm{L}$ genes on human renal cell carcinoma. Mol Ther 18: 544-551, 2010.

8 Ogata H, Chinen T, Yoshida T, Kinjyo I, Takaesu G, Shiraishi $\mathrm{H}$, Iida M, Kobayashi $\mathrm{T}$ and Yoshimura A: Loss of SOCS3 in the liver promotes fibrosis by enhancing STAT3-mediated TGFbeta1 production. Oncogene 25: 2520-2530, 2006.

9 Nishimura Y, Shimojima M, Tano Y, Miyamura T, Wakita T and Shimizu H: Human P-selectin glycoprotein ligand-1 is a functional receptor for enterovirus 71. Nat Med 15: 794-797, 2009.

10 Tuthill TJ, Groppelli E, Hogle JM and Rowlands DJ: Picornaviruses. Curr Top Microbiol Immunol 343: 43-89, 2010.

11 Mizushima T, Fukunaga M, Sueda T, Ikeda M, Kato T, Kim HM, Kudo T, Murata K, Nishimura J, Hata T, Matsuda C, Yamamoto H, Doki Y and Mori M: Phase I/II study of bi-weekly XELIRI plus bevacizumab treatment in patients with metastatic colorectal cancer resistant to oxaliplatin-based first-line chemotherapy. Cancer Chemother Pharmacol 80(1): 81-90, 2017.

12 Woynarowski JM, Faivre S, Herzig MC, Arnett B, Chapman WG, Trevino AV, Raymond E, Chaney SG, Vaisman A, Varchenko M and Juniewicz PE: Oxaliplatin-induced damage of cellular DNA. Mol Pharmacol 58: 920-927, 2000.

13 Luo FR, Wyrick SD and Chaney SG: Cytotoxicity, cellular uptake, and cellular biotransformations of oxaliplatin in human colon carcinoma cells. Oncol Res 10: 595-603, 1998.

14 Martuza RL, Malick A, Markert JM, Ruffner KL and Coen DM: Experimental therapy of human glioma by means of a genetically engineered virus mutant. Science 252: 854-856, 1991.

15 Pol J, Kroemer G and Galluzzi L: First oncolytic virus approved for melanoma immunotherapy. Oncoimmunology 5: e1115641, 2016.

16 Verheije $\mathrm{MH}$ and Rottier PJ: Retargeting of viruses to generate oncolytic agents. Adv Virol 2012: 798526, 2012.

17 Prestwich RJ, Errington F, Ilett EJ, Morgan RS, Scott KJ, Kottke T, Thompson J, Morrison EE, Harrington KJ, Pandha HS, Selby PJ, Vile RG and Melcher AA: Tumor infection by oncolytic reovirus primes adaptive antitumor immunity. Clin Cancer Res 14: 7358-7366, 2008.

18 Toda M, Rabkin SD, Kojima H and Martuza RL: Herpes simplex virus as an in situ cancer vaccine for the induction of specific antitumor immunity. Hum Gene Ther 10: 385-393, 1999.

19 Toda M, Martuza RL, Kojima H and Rabkin SD: In situ cancer vaccination: an IL-12 defective vector/replication-competent herpes simplex virus combination induces local and systemic antitumor activity. J Immunol 160: 4457-4464, 1998.

20 Thorne $\mathrm{SH}$ and Contag $\mathrm{CH}$ : Integrating the biological characteristics of oncolytic viruses and immune cells can optimize therapeutic benefits of cell-based delivery. Gene Ther 15: 753-758, 2008.

21 Diaconu I, Cerullo V, Hirvinen ML, Escutenaire S, Ugolini M, Pesonen SK, Bramante S, Parviainen S, Kanerva A, Loskog AS, Eliopoulos AG, Pesonen $\mathrm{S}$ and Hemminki A: Immune response is an important aspect of the antitumor effect produced by a CD40L-encoding oncolytic adenovirus. Cancer Res 72: 23272338, 2012.

22 Donnelly OG, Errington-Mais F, Steele L, Hadac E, Jennings V, Scott K, Peach H, Phillips RM, Bond J, Pandha H, Harrington K, Vile R, Russell S, Selby P and Melcher AA: Measles virus causes immunogenic cell death in human melanoma. Gene Ther 20: 7-15, 2013.

23 Kepp O, Galluzzi L, Martins I, Schlemmer F, Adjemian S, Michaud M, Sukkurwala AQ, Menger L, Zitvogel L and Kroemer G: Molecular determinants of immunogenic cell death elicited by anticancer chemotherapy. Cancer Metastasis Rev 30: 61-69, 2011.

24 Kanai R, Wakimoto H, Cheema T and Rabkin SD: Oncolytic herpes simplex virus vectors and chemotherapy: are combinatorial strategies more effective for cancer? Future Oncol 6: 619-634, 2010.

25 Sung CK, Choi B, Wanna G, Genden EM, Woo SL and Shin EJ: Combined VSV oncolytic virus and chemotherapy for squamous cell carcinoma. Laryngoscope 118: 237-242, 2008.

26 Nguyen A, Ho L and Wan Y: Chemotherapy and Oncolytic Virotherapy: Advanced Tactics in the War against Cancer. Front Oncol 4: 145, 2014.

27 Andoh A, Fujiyama Y, Sumiyoshi K, Sakumoto H, Okabe H and Bamba T: Tumour necrosis factor-alpha up-regulates decayaccelerating factor gene expression in human intestinal epithelial cells. Immunology 90: 358-363, 1997.

28 Burke-Gaffney A and Hellewell PG: Tumour necrosis factoralpha-induced ICAM-1 expression in human vascular endothelial and lung epithelial cells: modulation by tyrosine kinase inhibitors. Br J Pharmacol 119: 1149-1158, 1996.

29 Suzuki Y, Tanigaki T, Heimer D, Wang W, Ross WG, Murphy GA, Sakai A, Sussman HH, Vu TH and Raffin TA: TGF-beta 1 causes increased endothelial ICAM-1 expression and lung injury. J Appl Physiol (1985) 77: 1281-1287, 1994.

30 Cocuzzi ET, Bardenstein DS, Stavitsky A, Sundarraj N and Medof ME: Upregulation of DAF (CD55) on orbital fibroblasts by cytokines. Differential effects of TNF-beta and TNF-alpha. Curr Eye Res 23: 86-92, 2001.

31 Mason JC, Yarwood H, Sugars K, Morgan BP, Davies KA and Haskard DO: Induction of decay-accelerating factor by cytokines or the membrane-attack complex protects vascular endothelial cells against complement deposition. Blood 94: 1673-1682, 1999.

32 Chang YJ, Holtzman MJ and Chen CC: Interferon-gammainduced epithelial ICAM-1 expression and monocyte adhesion. Involvement of protein kinase C-dependent c-Src tyrosine kinase activation pathway. J Biol Chem 277: 7118-7126, 2002.

Received November 5, 2017

Revised December 4, 2017 Accepted December 11, 2017 